\title{
PRÁTICA PEDAGÓGICA: AS DIFICULDADES DOS PROFESSORES EM DESENVOLVER UMA PRÁTICA PEDAGÓGICA DE INCLUSÃO ESCOLAR
}

\author{
Maria das Graças Carvalho VILELA* \\ Thaís Coutinho de Souza SILVA**
}

Resumo: O presente artigo trata das dificuldades que o professor regente encontra em desenvolver uma prática pedagógica diária voltada para a inclusão escolar. Assim sendo, teve-se como principal objetivo analisar o processo de inclusão escolar de alunos com necessidades educacionais especiais, de ordem, física, intelectual e psicológica. De modo específico este estudo buscou ainda, descrever o processo histórico de inclusão escolar e a falta de formação adequada por parte do professor para receber o aluno com deficiência em sala de aula. Sem dúvida, a inclusão escolar é um dos maiores desafios que o professor se depara no desempenho de sua função, pois envolve não só o aluno com alguma necessidade educacional, física, intelectual ou psicológica especiais, como também envolve a escola, a família, a sociedade. Por essa razão, pesquisar sobre o processo de inclusão escolar é algo imprescindível e bastante justificável, tendo em vista que não basta inserir o aluno na sala de aula regular, é necessário se preocupar principalmente com o seu desenvolvimento e ter um acompanhamento cotidiano de sua aprendizagem, uma elaboração pedagógica

\footnotetext{
*Especialista em Coordenação Pedagógica pela Universidade Federal de Uberlândia. mgraca_carvalho@hotmail.com

${ }^{* *}$ Doutorado em Educação pela Universidade Federal de Uberlândia. thaiscoutinhoss@yahoo.com.br
} 
satisfatória, no intuito de valorizar suas potencialidades e propiciar sua interação os demais alunos. Para desenvolver essas reflexões foram utilizados os procedimentos técnicos da pesquisa bibliográfica e documental, que permitiram uma apreciação analítica dos textos, esboços, leis, decretos e portarias. A partir das análises é possível concluir que as dificuldades pedagógicas surgem como resultado da ausência de uma reflexão rigorosa por parte do professor sobre suas práticas e sobre a sua necessidade de formação.

Palavras-chave: Inclusão Escolar. Prática Pedagógica. Educação Básica.

Abstract: This article deals with the difficulties that the regent teacher finds in developing a daily pedagogical practice focused on school inclusion. Thus, the main objective was to analyze the process of school inclusion of students with special educational needs, of order, physical, intellectual and psychological. Specifically, this study also sought to describe the historical process of school inclusion and the lack of adequate training by the teacher to receive the student with disabilities in the classroom. Undoubtedly, school inclusion is one of the greatest challenges that the teacher faces in the performance of his or her function, as it involves not only the student with some special educational, physical, intellectual or psychological needs, but also involves the school, family, society. For this reason, research on the process of school inclusion is an essential and quite justifiable thing, since it is not enough to insert the student in the regular classroom, it is necessary to be concerned mainly with their development and to have a daily monitoring of their learning, a satisfactory pedagogical elaboration, in order to valorize their potentialities and provide their 
interaction with the other students. To develop these reflections were used the technical procedures of bibliographical and documentary research, which allowed an analytical appreciation of texts, sketches, laws, decrees and ordinances. From the analyzes it is possible to conclude that the pedagogical difficulties arise as a result of the absence of a rigorous reflection on the part of the teacher about their practices and about their need for training.

Keywords: School Inclusion. Pedagogical Practice. Basic education.

\section{INTRODUÇÃO}

A inclusão de pessoas com alguma necessidade especial à sociedade é um fato historicamente recente e que se apresenta a partir de uma série de tratados, leis e medidas públicas que têm sido aplicadas a fim de torná-la efetiva.

Nesse contexto, este artigo apresenta um estudo sobre as dificuldades encontradas pelos professores ao exercer uma prática pedagógica de inclusão escolar. Para nortear esta pesquisa buscou-se responder a seguinte pergunta: Quais os entraves que alguns docentes enfrentam para desenvolver uma metodologia e uma prática pedagógica voltada para a inclusão escolar?

(C) Vilela; Silva - DiversaPrática, v. 4, n. 1, p.90 -121 - $1^{\circ}$ semestre 2017 
A partir desta questão, o estudo objetivou identificar e analisar os entraves que os docentes enfrentam no exercício de sua prática, para efetivar o processo de inclusão escolar de alunos com necessidades educacionais especiais em decorrência de um quadro de deficiência, transtornos globais do desenvolvimento e/ou altas habilidades/ superdotação, tendo ainda, como objetivo específico, descrever o processo histórico pelo qual perpassa a inclusão escolar e a deficitária formação por parte do professor para receber o aluno com deficiência em sala de aula.

Sendo assim, este estudo apresenta grande relevância ao propiciar uma reflexão sobre as práticas docentes perante a inclusão escolar obrigatória, quanto ao papel do professor acerca da inclusão, ocorrências (ou inocorrência) de suporte pedagógico, de treinamento específico e apoio financeiro. Tudo isso, visando a educação inclusiva constituinte de um paradigma educacional fundamentado na concepção de direitos humanos, que conjuga igualdade e diferença como valores e que avança em relação à ideia de equidade formal ao contextualizar as circunstâncias históricas da produção da exclusão dentro e fora da escola.

Assim, a inclusão vai se tornando um processo incidente na realidade educacional, fazendo-se necessário efetivar um estudo mais 
aprofundado dessa temática com a preocupação de oferecer uma inclusão escolar de qualidade para os alunos com deficiência na sala de aula regular de ensino.

Para desenvolver este estudo escolheu-se o tipo pesquisa bibliográfica, buscando em autores renomados na área, contribuições para uma discussão significativa de modo a construir um embasamento teórico que permitisse analisar, sobre diversos aspectos, o tema proposto e identificar os possíveis caminhos e soluções aos problemas encontrados. Para a análise das Leis, Decretos e Portarias, foram utilizados os procedimentos da pesquisa documental que permitiram uma maior compreensão do conteúdo estudado.

Dentre os trabalhos pesquisados é possível destacar alguns autores de maior relevância para a construção dos dados, tais como, Glat (2007), Mantoan (2005), Monteiro (2003) e Paulon (2005).

\section{DESENVOLVIMENTO}

\subsection{A origem do processo de Inclusão Escolar}

Não é necessário ir muito longe na história para perceber que os problemas sociais enfrentados pelas pessoas com necessidades especiais acompanham a humanidade desde a origem da civilização. É

(C) Vilela; Silva - DiversaPrática, v. 4, n. 1, p.90 -121 - $1^{\circ}$ semestre 2017 
possível, como afirmam Souza (2010), Diáz et al. (2009), comprovar através de registros históricos a nítida resistência da sociedade ao processo de aceitação de pessoas com necessidades especiais. Estes documentos podem demonstrar, inclusive, como a vida de uma pessoa com deficiência e algum tipo de necessidade especial era, sobretudo, ameaçada.

De acordo com Bernardes (2010) e Marconcin (2013), até o século XVI não havia na sociedade a preocupação em oferecer atendimento educacional às pessoas consideradas "diferentes" das demais.

Ainda, segundo os mesmos autores, durante toda a história, pessoas com alguma doença mental, dificuldade em falar, ou alguma deformidade física, foram excluídas dos processos de aprendizagem formal ou acadêmica, e, sobretudo, da participação ativa em sociedade unicamente ou especificamente em virtude das diferenças que apresentavam. Tudo isto, atribuído ao fato de não se enquadrar em um padrão específico principalmente físico e comportamental que, articulado inicialmente por necessidades físicas, de sobrevivência ou de seleção natural, passou a tornar-se um motivo para a classificação pejorativa de uma classe supostamente considerada subumana por não ter utilidade para a vida em sociedade.

(C) Vilela; Silva - DiversaPrática, v. 4, n. 1, p.90 -121 - $1^{\circ}$ semestre 2017 
Entre os romanos, na Grécia Antiga e também na Idade Média, a deficiência era concebida como obra de maus espíritos e as pessoas com necessidades especiais eram tratadas como "animais" sendo aprisionadas, e até mesmo condenadas à morte.

Como explicam Silva et al. (2006),

[...] nas sociedades escravistas, grega e romana, verificou-se a supervalorização do corpo perfeito, da beleza e da força física, pois estas dedicavam-se predominantemente à guerra, que tinha a finalidade de conquistar escravos e manter a ordem vigente. Nessas sociedades, amparados em leis e em costumes, se uma criança apresentasse, ao nascer, algum "defeito" que viesse a se contrapor de alguma forma ao ideal proposto era eliminada ou abandonada semque isso fosse considerado crime (SILVA et al., 2006, p. 4).

Os autores ainda afirmam que a justificativa para a época era embasada no imaginário social onde tais pessoas eram consideradas como improdutivas, inúteis e incapazes, sendo tomadas como um fardo pesado ou uma cruz a ser carregada pela família e pela sociedade. Silva et al., (2006, p. 1) ainda afirmam que "este modelo de se ver, compreender e tratar as pessoas com deficiência não é próprio de uma classe da sociedade e nem de seu setor menos esclarecido”. 
A naturalidade em aceitar e sustentar este tipo de tratamento, segundo esses autores, está no fato de que, na maioria dos casos, a:

[...] característica principal das sociedades primitivas era o baixíssimo nível de desenvolvimento das forças produtivas, o que obrigava os homens a viverem no nomadismo, onde suas condições de existência estavam totalmente na dependência do que a natureza lhes proporcionava, ou seja, a coleta de frutos, a caça e a pesca, no que se refere à alimentação, e as cavernas no tocante a abrigos (SILVA et al., 2006, p. 5)

Conforme as mudanças ocorridas nas sociedades, tanto em suas formas de produção, quanto em suas concepções religiosas, a forma de visualizar pessoas com necessidades educacionais especiais em decorrência de um quadro de deficiência passou a transformar-se também.

Como mostram Silva et al., (2006, p. 5), ao final da Idade Média, uma pessoa que apresentasse algum tipo de deficiência era vista somente sob o aspecto místico. Assim, sua deficiência poderia ser atribuída ao resultado da ação de forças demoníacas, ao castigo para pagamento de seus pecados ou de seus ancestrais, e ainda, a um instrumento para que se manifestassem as obras de Deus. 
É no século XVIII que se situa a criação das primeiras instituições fillantrópicas destinadas a atender cegos e surdos, como afirmam Pacheco e Costas (2005). Ainda segundo os mesmos autores, apenas no século $\mathrm{XX}$, as instituições motivadas por lutas sociais em torno dos direitos humanos ampliaram o atendimento especializado a diversos grupos excluídos. Sincronicamente, é possível afirmar que este processo reflete cada vez mais a alternância de concepções atribuídas às pessoas com necessidades educacionais especiais, que gradativamente passam a ser preocupação da sociedade atribuída tanto pelos preceitos morais quanto religiosos dos grupos sociais.

No Brasil, o atendimento às pessoas com deficiência teve início na época do Império com a criação do Imperial Instituto dos Meninos Cegos, em 1854, que é o atual Instituto Benjamin Constant - IBC, e do Instituto dos Surdos, em 1857, atual Instituto Nacional da Educação dos Surdos - INES, ambos no Rio de Janeiro. No início do século XX é fundado o Instituto Pestalozzi, especializado no atendimento às pessoas com deficiência mental; em 1954 foi fundada a primeira Associação de Pais e Amigos dos Excepcionais (APAE), e, em 1945 é criado o primeiro atendimento educacional especializado às pessoas com superdotação na Sociedade Pestalozzi como podemos ver na Portaria

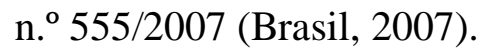

(C) Vilela; Silva - DiversaPrática, v. 4, n. 1, p.90 -121 - $1^{\circ}$ semestre 2017 
De acordo com a Lei n. ${ }^{o}$ 4024/1961, na década de 1960, o atendimento educacional às pessoas com deficiência passa a ser fundamentado pela Lei de Diretrizes e Bases da Educação Nacional, de acordo com a Lei $\mathrm{n}^{\circ}$ 4.024/61 o direito dos excepcionais à educação. Em 1973, foi criado no MEC, o Centro Nacional de Educação Especial (CENESP), responsável pela gerência da educação especial no Brasil.

Em seguida, com a criação do Estatuto da Criança e do Adolescente surge a Lei ${ }^{\circ}$ 8.069/90 que, em seu artigo 55, reforça os dispositivos legais supracitados, ao determinar que pais ou responsáveis tenham a obrigação de matricular seus filhos ou pupilos na rede pública de ensino regular.

Ainda nesta década, surgem documentos importantes para a inclusão de pessoas com algum tipo de deficiência, principalmente através da Declaração Mundial de Educação para Todos e da Declaração de Salamanca, em 1994, que formulam as políticas públicas voltadas à educação inclusiva.

Com o desenrolar de tratados e convenções, a atual Lei de Diretrizes e Bases da Educação Nacional (LDB no 9.394/96) afirma em seu artigo Art. 59, que:

Os sistemas de ensino assegurarão aos educandos com deficiência, transtornos globais do desenvolvimento e 
altas habilidades ou superdotação: (Redação dada pela Lei $n^{\circ}$ 12.796, de 2013) I - currículos, métodos, técnicas, recursos educativos e organização específicos, para atender às suas necessidades (BRASIL, 1996).

Podendo, desta forma, assegurar o resultado dos que não atingiram o nível exigido para a conclusão do ensino fundamental, em virtude de suas deficiências. Acompanhando o processo de mudanças, a Resolução CNE/CEB n ${ }^{\circ} 2 / 2001$, no Art. $2^{\circ}$, determina que:

Os sistemas de ensino devem matricular todos alunos, cabendo às escolas organizar-se para o atendimento aos educandos com necessidades educacionais especiais, assegurando as condições necessárias para uma educação de qualidade para todos (BRASIL, 2001).

Já o Decreto $n^{\circ}$ 6.094/2007 estabelece, dentre as diretrizes do Compromisso "Todos pela Educação", a garantia do acesso e permanência no ensino regular e ao atendimento às necessidades especiais de alunos, fortalecendo a inclusão educacional nas escolas.

Mesmo com a aplicação de todas estas medidas, alguns autores como, por exemplo, Dantas (2007) afirmam existir uma grande parte da população brasileira que sofre com a fragilidade das políticas públicas as quais não têm demonstrado eficiência e eficácia quanto ao acesso 
desta população à saúde, educação, habitação e assistência social e, desse modo, com relação à educação inclusiva a situação não seria diferente.

Segundo Brasil (2008,p.10), o entendimento de que a educação especial deve ser organizada de forma paralela à educação comum seria mais apropriada para a aprendizagem dos alunos que apresentavam deficiência, problemas de saúde, ou qualquer inadequação com relação à estrutura organizada pelos sistemas de ensino perdurou por muito tempo. Desta forma, exerceu impacto duradouro na história da educação especial, o que resultou em práticas que enfatizam os aspectos relacionados à deficiência, em contraposição à dimensão pedagógica. Assim, o desenvolvimento de estudos no campo de educação e a defesa dos direitos humanos vêm modificando os conceitos, as legislações e as práticas de gestão, promovendo a reestruturação do ensino regular e especial.

Assim sendo, percebe-se que há um processo de transformação nas escolas, entretanto, o que tem sido feito a fim de modificar as concepções internas das instituições que envolvam principalmente as práticas pedagógicas dos professores? A transformação da escola, conforme o documento elaborado pelo Ministério Público (2004), não é "uma mera exigência da inclusão escolar de pessoas com deficiência 
e/ou dificuldades de aprendizado. Assim sendo, ela deve ser encarada como um compromisso inadiável das escolas, que terá a inclusão como consequência”.

Entretanto, dentro das escolas, surgem dúvidas frequentes com relação à forma de abordagem, tratamento (diferenciado ou não) e forma de avaliação que devem ser dispensados aos alunos com necessidades educacionais especiais. Assim como afirma Monteiro (2003), até a forma de classificação e nivelamento dos alunos gera conflito, sendo comum presenciar professores especializados se referindo aos seus alunos como "as crianças" ou desenvolvendo propostas com objetivos e interesses relacionados à educação infantil, ainda que se trate de jovens e adultos entre dezessete e vinte anos de idade, ou até, maior idade. Este tipo de inclusão seria baseado na idade mental.

Segundo o mesmo autor, realizar a inclusão escolar baseada na idade mental como critério para a decisão sobre a escolha da turma a ser "incluído" o aluno com deficiência, pode acarretar o assentamento das desigualdades em situações de interação que se estabelecem, o que provoca um abismo maior entre os interesses e a necessidades do aluno com deficiência intelectual. O aluno com necessidades educacionais especiais, na maioria dos casos, passa a ser visto como o desordenado 
da turma, culpado de todos os conflitos, com comportamentos inadequados e causador de problemas que possam vir a acontecer em decorrência dessas incompatibilidades.

Assim como estabelecido pelo Documento Subsidiário à Inclusão (Brasil, 2005), o processo de inclusão educacional deve levar em conta o ser humano em diversos aspectos ao definir uma proposta educacional. Neste ponto, a importância do planejamento, do trabalho em equipe, da gestão escolar e das práticas pedagógicas fica evidente.

Tal proposta permite refletir sobre o posicionamento que a escola assume acerca do assunto e impossibilita que o fato seja ignorado, visto que as possibilidades de desenvolvimento cognitivo e de aprendizagem dos alunos com deficiência intelectual estão diretamente relacionadas com o processo educacional e com o meio social.

Com relação a este processo, Mantoan (1999), analisa o papel das escolas no processo de inclusão e nos afirma que ele:

[...] só poderá ter êxito quando as escolas passarem a diminuir os obstáculos que sempre existiram à inclusão de alunos com deficiência intelectual, em decorrência de os currículos adotados se basearem em práticas homogêneas, em avaliações classificatórias, em aulas pouco criativas e sem espaço para o trabalho em

(C) Vilela; Silva - DiversaPrática, v. 4, n. 1, p.90 -121 - $1^{\circ}$ semestre 2017 
cooperação, entre outros aspectos (MANTOAN, 1999, p.99).

A mesma autora ainda nos mostra em seu livro "Inclusão Escolar. O que é? Porque? Como se faz?"(2003), a construção de práticas pedagógicas como alternativas de inclusão escolar e traz como prioridade a competência intelectual sob a afirmação de que alunos com necessidades educacionais especiais têm o direito de viver para desenvolver suas capacidades. Outros pontos essenciais para este desenvolvimento são: a conquista da autonomia, trazendo sobre si o direito de decidir e escolher segundo suas necessidades e motivações; e o direito de se desenvolver como as demais pessoas, em ambientes que não discriminem, mas valorizem as diferenças, isto consumado através do meio social no processo interativo de produção.

Paulon, Freitas e Pinho (2005) afirmam, entretanto, que os desafios da inclusão são notórios quando se referem à alternância na forma de realização da educação regular e especial, através das mudanças curriculares. O importante é lembrar que todas as mudanças realizadas no currículo que incluem a educação especial, assim como qualquer outra mudança, possuem como intuito a efetivação do conhecimento por parte do aluno nos níveis mais próximos possíveis dos objetivos, conteúdos e critérios propostos aos demais. Então, 
caberia a todas as instâncias garantir a efetividade na aplicação das mudanças curriculares que abordam a inclusão escolar.

Com relação ao professor e às suas práticas docentes relacionadas à inclusão escolar que busque efetivar o ensino e a aprendizagem, procuramos apontar alguns caminhos que poderiam sugerir práticas pedagógicas voltadas a alunos que apresentem alguma dificuldade intelectual. Nesse contexto, Rodrigues (1999) sugere,

Adotar metodologias de ensino diversificadas, que comtemplem estilos de aprendizagem variados; Solicitar informações ou atuações com ordens claras e sequenciais, em lugar de instruções gerais, explicações muito longas e pouco precisas; Favorecer, sempre que possível a experiência direta, acompanhada de demonstração e mediação de um professor mais experiente; Desenvolver práticas que favoreçam a mediação do professor e dos colegas; Priorizar atividades e solicitar tarefas de duração breve. Com objetivos distintos; Estimular a demonstração de habilidades e talentos individuais que a o conhecimento formal em tarefas que exijam trabalhos e ajuda mútua; Mudar a rotina de sala de aula em relação a organização do espaço físico; Avaliar o progresso diário do aluno, sua aprendizagem utilizando suas próprias produções como parâmetro, evitando comparações com os demais (RODRIGUES, 1999, p. 99).

Ainda, segundo o mesmo autor, caberia ao professor o papel de estimulador do desenvolvimento das várias formas de comunicação e 
interação que oportunizariam ao aluno a maior possibilidade de estabelecer suas habilidades e expressões. Entretanto, a partir das discussões deste capítulo, é possível chegar à seguinte indagação: será que o professor, principalmente da educação básica da rede pública de ensino, possui meios para que isto aconteça com efetividade conforme é incumbido?

\subsection{Dificuldades na prática pedagógica}

Em 2006 foi estabelecido que todos os estados brasileiros devessem garantir a existência de um "sistema de educação inclusiva em todos os níveis de ensino, em ambientes que maximizem o desenvolvimento acadêmico e social compatível com a meta de inclusão plena" (BRASIL, 2008). Desta forma, garantindo que pessoas com alguma deficiência não sejam excluídas do sistema educacional, também foi instituída a garantia às pessoas com necessidades específicas o acesso ao ensino fundamental inclusivo, de qualidade e gratuito, em igualdade de condições com as demais pessoas na comunidade em que vivem.

Conforme afirma Sousa (2010), a educação inclusiva vive, atualmente, uma dinâmica de transformação, principalmente no que se 
refere à concepção e às diretrizes, e trazem um contexto de afirmação “do compromisso de estabelecer um plano de ação político pedagógico para área, que envolva a perspectiva de inclusão das pessoas com deficiência" (SOUSA, 2010). Dessa forma, percebe-se a dualidade de concepções com relação à inclusão. De um lado, a existência e a permanência de centros especializados para pessoas com necessidades educacionais especiais em decorrência de um quadro de deficiência. De outro, a escola de educação básica regular que passa a trazer, incumbida em suas obrigações, o acolhimento aos alunos com deficiência e a garantia de sua formação regular, além, de manter o mesmo ritmo na formação de alunos que não possuem necessidades educacionais especiais.

Uma vez que as escolas públicas devem incluir os alunos com deficiência juntamente com os alunos que não as possuem, os investimentos em tecnologias, aperfeiçoamento de profissionais, infraestrutura, material adequado, tornam-se indispensáveis. Desta forma, para que o processo de inclusão ocorra com efetividade é preciso que haja investimentos e segundo Ribeiro, Lima e Santos (2009) se torna,

[...] imprescindível que as instituições de ensino que atuam com alunos com NEE [Necessidades Especiais 
Específicas] adaptem-se fisicamente para a inserção dos mesmos e tenham seu quadro docente formado por profissionais aptos a trabalhar com os respectivos alunos, de modo que possam atender as diferenças individuais e o desenvolvimento de suas potencialidades, criando condições concretas de aprendizagem e capacitando-as para sua inserção ao mercado de trabalho (RIBEIRO; LIMA; SANTOS, 2009, p. 94).

Ribeiro, Lima e Santos (2009) ainda afirmam que:

[...] a escola inclusiva precisa possuir um bom projeto pedagógico, diante do qual, toda a equipe escolar irá discutir tentar entender, promover transformações em sua organização e funcionamento, visando atender aos diversos tipos de necessidades. É fundamental também, que os professores desenvolvam o domínio teóricoprático sobre as concepções de ensino e aprendizagem, buscando sempre o aperfeiçoamento de sua prática, mediante observação sistemática dos avanços e necessidades/dificuldades dos alunos (RIBEIRO, LIMA E SANTOS, 2009, pg. 94-95)

Assim, os resultados do processo de aprendizagem e o rendimento dos alunos acabam incumbidos não somente à instituição de ensino, mas principalmente aos professores e às suas práticas pedagógicas. Com isso acaba-se tornando fundamental que "o professor seja um estudioso e um investigador dos resultados de sua atuação, a fim de aperfeiçoar sua prática" (RIBEIRO; LIMA; SANTOS, 2009, p. 95). Neste sentido, a atitude e o caráter de ensino do docente durante a 
abordagem educacional representam fatores primordiais para assegurar o êxito de todos.

Logo, uma nova abordagem educacional pressupõe "pensar o ensino a partir de uma atitude aberta, flexível e, sobretudo, reflexiva em relação à própria prática educacional" (RIBEIRO, LIMA E SANTOS 2009, p. 95). Uma vez que “o princípio fundamental das escolas inclusivas consiste em todos os alunos aprenderem juntos, sempre que possível, independentemente das dificuldades e das diferenças que apresentam" (CARVALHO, 1997, p. 22).

Contudo, essa não é uma tarefa fácil, além de medidas externas, Perrenoud (2000) aponta a administração da formação contínua como a competência mais importante dos docentes, uma vez que ela condiciona o desenvolvimento de todas as outras. Desta forma, torna-se imprescindível o desenvolvimento do domínio teórico-prático sobre as concepções de ensino e aprendizagem por parte dos professores e a permanência da formação continuada.

Logo, como afirmam Ribeiro, Lima e Santos (2009), para que haja uma nova abordagem educacional, principalmente no que tange ao processo de inclusão, é necessário repensar o ensino. Através de pesquisas feitas por estes autores, é possível constatar alguns aspectos importantes para essa temática como a existência inquestionável de

(C) Vilela; Silva - DiversaPrática, v. 4, n. 1, p.90 -121 - $1^{\circ}$ semestre 2017 
dificuldades vividas pelos alunos com alguma necessidade especial no processo de aprendizagem. Na tentativa de evitar este problema, eles destacam que,

[...] em 2004, a Unesco publicou o material voltado para a formação de professores denominado Mudando as práticas de ensino: usando diferenciação curricular para responder a diversidade na sala de aula, cujo conteúdo, pode ser válido para contribuir com a prática docente já que o mesmo explicita como o professor pode diferenciar a apresentação, a maneira de promover as atividades e a avaliação do conteúdo curricular no sentido de ajudar todos os alunos a aprenderem e participarem mais ativamente em sala de aula (RIBEIRO, LIMA E SANTOS, 2009, p. 97, GRIFO DO AUTOR).

A partir desta publicação surgem as seguintes indagações: Será que um material de práticas prontas seria a solução adequada a todos os problemas relacionados à inclusão nas escolas? A simples adaptação de um material genérico distribuído para todo o país seria a solução? As práticas pedagógicas poderiam ser genericamente afetadas por materiais publicados? Como garantir a educação inclusiva?

Para tanto, é possível identificar que as dúvidas e obstáculos acerca do processo de inclusão são inúmeros. No que se refere às dificuldades que o docente enfrenta, Monteiro (2003) afirma que durante o processo de inclusão podem surgir diversas situações em que 
as decisões do professor sobre a didática que será aplicada ao aluno, são expressas pela sua responsabilidade de ensinar e evitar que este aluno que está sendo incluído caia em fracasso escolar. Tal atitude pode demonstrar que o professor visualiza a necessidade de maior empenho na sua ação. Porém, este interesse pode cair em vias de tornar-se seletivo e contraditório uma vez que o professor corre o risco de centrar sua preocupação em incluir e ao mesmo tempo findar em excluir os outros alunos das atividades desenvolvidas em sala de aula. Esta atitude pode levar ao êxito do aluno incluído, porém pode levar também ao ócio do restante da turma enquanto espera o professor auxiliá-lo. Em muitos casos, pode ocasionar desordem na sala de aula e até mesmo se tornar um processo cíclico durante todas as aulas.

Este tipo de abordagem docente requer maior planejamento e sistematização de seu trabalho, a fim de acolher a todos os alunos, além de um preparo mais cuidadoso das atividades a serem desenvolvidas, o que não é uma tarefa fácil, visto que o professor é obrigado a sair da sua zona de conforto e despender muito tempo em planejamento e realização dos mínimos detalhes das aulas.

Sobre diversas perspectivas, a realização deste tipo de atividade pode tornar-se um processo exaustivo, que levaria o professor a se desgastar de forma física e psicológica para conseguir atingir seus

(C) Vilela; Silva - DiversaPrática, v. 4, n. 1, p.90 -121 - $1^{\circ}$ semestre 2017 
objetivos em sala de aula. Isto poderia ser consequência do que Rodrigues (2006) afirma ser a confirmação da legislação e do discurso a fim de tornarem a escola rapidamente "inclusiva" enquanto as práticas na escola só muito discretamente tendem a ser mais "integrativas".

O mesmo autor ainda afirma que com relação à inclusão, o discurso está muito longe das práticas. Isso porque, a escola está mais próxima da concepção Integrativa que:

[...] separava os alunos em dois tipos: os "normais" e os "deficientes". Para os alunos "normais" era mantida a sua lógica curricular, os mesmos valores e práticas; para os "deficientes" selecionava condições especiais de apoio ainda que os aspectos centrais do currículo continuassem inalterados. A escola Integrativa "via" a diferença só quando ela assumia o carácter de uma deficiência e neste aspecto encontrava-se bem longe de uma concepção inclusiva (RODRIGUES, 2006, p. 9).

Segundo Ribeiro, Lima e Santos (2009), formação continuada se desenvolve na busca pelo "aperfeiçoamento de suas práticas, mediante observação sistemática dos avanços e necessidades/dificuldades dos alunos". Sendo assim, deve partir de uma iniciativa tanto do professor, quanto das instituições.

Com relação ao processo de inclusão nas escolas de educação básica, uma série de medidas e iniciativas públicas entre cursos, 
cartilhas, reciclagens foram tomadas a fim de capacitar os professores. Entretanto, somente estas atitudes não são suficientes para tornar efetivo o processo de inclusão. Rodrigues (2006) aponta duas questões ligadas a este processo: a primeira, relacionada à complexidade de ser professor e a segunda, relacionada ao que é feito com o conhecimento. Em suas palavras ou autor aponta que,

Um professor não é um técnico (no sentido de aplicar técnicas relativamente normalizadas e previamente conhecidas) nem é um funcionário (isto é, uma pessoa que executa funções enquadradas por uma cadeia hierárquica perfeitamente definida). [...] professor exige uma grande versatilidade [...] e seja capaz de delinear e desenvolver planos de intervenção em condições muito diferentes. [...] Não podemos esquecer quais foram os interesses que esse conhecimento serviu [...]. O conhecimento da diferença não é sempre positivo; podemos conhecer para melhor segregar (RODRIGUES, 2006, p. 6).

Regressando ao domínio da educação, Monteiro (2003) e Rodrigues (2006) afirmam que em cursos de formação de professores para a prática inclusiva, a ênfase deve ser dada a conhecer as diferenças a fim de articular a inclusão e não a justificar a segregação.

Conhecer as diferenças mais comuns que são certamente as mais numerosas. Enfim não dar a conhecer a diferença como se se tratasse de uma situação médica mas fazer

(C) Vilela; Silva - DiversaPrática, v. 4, n. 1, p.90 -121 - $1^{\circ}$ semestre 2017 
acompanhar cada caracterização de indicações pedagógicas que contribuam para que o futuro professor possua um esboço de entendimento que lhe permita iniciar o seu processo de pesquisa (RODRIGUES, 2006, p. 7).

\section{CONSIDERAÇÕES FINAIS}

Propôs-se, com este estudo, refletir sobre as dificuldades dos professores diante da inclusão escolar de pessoas com necessidades educacionais especiais, visto que, é essencial que o professor busque inovar-se, produzir sempre mais conhecimento, pois todo o conhecimento que vier a construir no dia a dia, no contexto da educação inclusiva em sala de aula, no atendimento a essas crianças, será sempre pouco porque todos os dias estará reciclando e adquirindo novos conhecimentos.

Para se configurar uma educação inclusiva em uma instituição de ensino, toda a comunidade escolar deve estar envolvida além, é claro, da construção do projeto político pedagógico da escola. Abranger claramente a abordagem que deve ser feita quanto à inclusão visando atingir diferentes estilos de aprendizagem e diversos tipos de necessidades e pluralidade cultural dos alunos, segundo afirmam Ribeiro, Lima e Santos (2009) e Rodrigues (2006).

(C) Vilela; Silva - DiversaPrática, v. 4, n. 1, p.90 -121 - $1^{\circ}$ semestre 2017 
$\mathrm{O}$ ato de incluir um aluno com alguma deficiência passa a ter o sentido de trazer o aluno à realidade da escola e a escola deve se adaptar às necessidades do aluno. Para que isto aconteça, uma série de medidas públicas vem sendo tomadas. Entretanto, como afirmam Rodrigues (2006) e Ribeiro, Lima e Santos (2009), somente o planejamento e a sistematização não são suficientes.

O processo de inclusão é visto, na maioria das vezes, como um desafio imposto, que deve ser enfrentado pela instituição de ensino e principalmente pelo professor. Este último se depara com a necessidade de se capacitar e atualizar suas práticas de ensino. Entretanto, não há uma receita pronta para o processo de inclusão. Como resultado, os professores podem vir a sentir-se despreparados ou frustrados e, sobretudo, desamparados diante deste desafio.

Tais dificuldades são muitas vezes derivadas da maneira como o professor organiza suas atividades, da ausência de metodologias diferenciadas e de recursos didáticos específicos, além de critérios de avaliação que não respondem de modo satisfatório aos alunos com necessidades especiais.

Assim, conclui-se que o processo de ensino-aprendizagem de alunos com ou sem deficiência ocorre num processo de respeito, diálogo e trocas de vivências. Se o educador conseguir propiciar a seu

(C) Vilela; Silva - DiversaPrática, v. 4, n. 1, p.90 -121 - $1^{\circ}$ semestre 2017 
educando um ambiente saudável, estimulante e facilitador da aprendizagem, não haverá deficiências no ambiente escolar e, nem mesmo, diferenças de tratamento, mas haverá uma prática pedagógica diferenciada para cada necessidade. Por isso, é importante a formação do professor de maneira continuada para que se tenha um embasamento teórico que modifique práticas pedagógicas retrógadas, a fim de reconstruir o ato de ensinar e aprender.

\section{REFERÊNCIAS}

BERNARDES, A. O. Da integração à inclusão, novo paradigma. 2010. Disponível em:

<http://www.educacaopublica.rj.gov.br/biblioteca/educacao/0252.html $>$. Acesso em: 10 jan. 2016.

BRASIL. Ministério da Educação. Lei n 9394/96 de 20 de dezembro de 1996. Lei de Diretrizes e Bases da Educação Nacional. Diário Oficial da Replica Federativa do Brasil. Brasília: MEC, 1996.

Ministério da Educação. Política nacional de educação especial na perspectiva da educação inclusiva. Portaria $\mathrm{n}^{\circ} 555 / 2007$, prorrogada pela Portaria n ${ }^{\circ}$ 948/2007. Disponível em:

<http://portal.mec.gov.br/arquivos/pdf/politicaeducespecial.pdf>. Acesso em: 18 jan. 2016.

(C) Vilela; Silva - DiversaPrática, v. 4, n. 1, p.90 -121 - $1^{\circ}$ semestre 2017 
. Procuradoria Federal dos Direitos do Cidadão. $\mathbf{O}$ acesso de alunos com deficiência às escolas e classes comuns da rede regular. 2004. Disponível em: <http://pfdc.pgr.mpf.mp.br/atuacao-econteudos-de-apoio/publicacoes/pessoa-comdeficiencia/acesso_alunos_ensino_publico_2004>. Acesso em: 15 jan. 2016.

DANTAS, M. Construção de Políticas Públicas para População em Situação de Rua no Município do Rio de Janeiro: Limites, Avanços e Desafios. 2007. Disponível em:

<http://www.arca.fiocruz.br/xmlui/bitstream/handle/icict/5015/900.pd f?sequence=2>. Acesso em: 18 jan. 2016.

DIÁZ, F. et al. Educação inclusiva, Deficiência e contexto social: questões contemporâneas. Salvador: EDUFBA, 2009. Disponível em: <http://www.ufjf.br/acessibilidade/files/2009/07/EducacaoInclusiva.pdf>. Acesso em: 10 jan. 2016.

EDLER C. R. Educação inclusiva com os pingos nos is. Porto Alegre: Mediação, 2004.

FREIRE, P. Pedagogia da Autonomia: Saberes necessários à pratica educativa. São Paulo: Paz e Terra, 1976. MANTOAN, M. T. E. (org.). Inclusão Escolar. O que é? Porque? Como se faz? São Paulo: Moderna, 2003. 
MANTOAN, M. T. E. A hora da virada: inclusão. Revista da Educação Especial: Brasília, v. 1, n.1, 2005, p.24-28.

MARCONCIN, L. I. R. P. et al. O olhar do surdo: traduzindo as barreiras no ensino superior. 2013. Revista Eletrônica do Curso de Pedagogia das Faculdades OPET. Disponível em:

<http://www.opet.com.br/faculdade/revistapedagogia/pdf/n5/ARTIGO -RISCILA.pdf $>$. Acesso em: 10 jan. 2016.

MONTEIRO, A. T. M. Educação inclusiva: um olhar sobre o professor. 2003. Disponível em:

<http://www.bibliotecadigital.ufmg.br/dspace/bitstream/handle/1843/ FAEC-85VK7H/1000000517.pdf?sequence=1>. Acesso em 18 jan. 2016.

PACHECO, R. V.; COSTAS, F. A. T. O processo de inclusão de acadêmicos com necessidades educacionais especiais na Universidade Federal de Santa Maria. 2005. Disponível em: <http://coralx.ufsm.br/revce/ceesp/2006/01/a12.htm>. Acesso em 18 jan. 2016.

PAULON, S. M.; FREITAS, L. B. L.; PINHO, G. S. Documento subsidiário à política de inclusão. Ministério da Educação.

Secretaria de Educação Especial. Brasília: MEC, 2008. 2005. 48p. Online. Disponível em: 
<http://portal.mec.gov.br/seesp/arquivos/pdf/revistainclusao1.pdf>. Acesso em: 19 jan. 2016.

PERRENOUD, P. 10 novas competências para ensinar. Porto Alegre: Artes Médicas, 2000.

RIBEIRO, G. F.; LIMA, T. S.; SANTOS, M. C. Inclusão escolar em Feira de Santana: caracterização da prática pedagógica In: RIBEIRO, G. F.; LIMA, T. S.; SANTOS, M. C. Educação inclusiva, Deficiência e contexto social: questões contemporâneas. Salvador: EDUFBA, 2009. Disponível em: <http://www.ufjf.br/acessibilidade/files/2009/07/EducacaoInclusiva.pdf > . Acesso em: 10 jan. 2016.

RODRIGUES, D. Dez ideias (mal) feitas sobre a Educação Inclusiva. 2006. Disponível em: $<$ http://redeinclusao.web.ua.pt/docstation/com_docstation/21/fl_47.pd f>. Acesso em: 22 jan. 2016.

SAVIANI, N. Currículo: um grande desafio para o professor. São Paulo: Revista de educação, n 16, 2003, p. 35-38.

SILVA, S.; VIZIM, M. Educação Especial: múltiplas leituras e diferentes significados. Campinas: Mercado de Letras, 2001. 
SOUSA. R. F. Inclusão no Ensino Regular. 2010. Disponível em: <http://www.pedagogia.com.br/artigos/ensinoregular/>. Acesso em: 11 jan. 2016.

RIBEIRO, G. F.; LIMA, T. S.; SANTOS, M. C. Inclusão escolar em Feira de Santana: caracterização da prática pedagógica. In: DÍAZ, F. et al. (orgs). Educação inclusiva, deficiência e contexto social: questões contemporâneas. Salvador: EDUFBA, 2009, p. 91-98. 